\title{
How do surgeons decide on the extent of resection for patients with lung cancer?
}

\author{
Eric Lim, MBChB, MD, MSc (Biostatistics), FRCS(C-Th)
}

See related article on pages 507-13.

What's the difference between God and a surgeon? You must have heard this worn-out joke hundreds of times-God does not think he is a surgeon. Like it or not, our specialty is often regarded to be replete with big egos that are shy to acknowledge different surgeons have different abilities and skills in performing surgery.

In this issue of the Journal, Camposilvan and colleagues $^{1}$ report on the procedures offered to patients with the US healthcare setting highlighting variation in the extent of resection related to individual surgeon volume. Surgeons with higher surgical volume were associated with an increased odds of undertaking lobectomies compared with surgeons with lower volume with higher odds of performing pneumonectomies and wedge resections.

Because outcomes were derived from registry data, it is impossible to determine the reasons for the differences influencing the extent of resection. The unstated view posed by Camposilvan and colleagues ${ }^{1}$ is that all things being equal (ie, surgical skill), the selection of procedures should be roughly the same among all surgeons regardless of volume. In theory, it could be possible that surgeons with lower volume are seeing more central tumors and patients with severely impaired lung function, resulting in more pneumonectomies and wedge resections, respectively. But data from the United Kingdom are at odds with this argument; it was observed that higher-volume centers tended to see patients with more advanced-stage disease and increased comorbidities and still achieve better outcomes. $^{2}$

\footnotetext{
From The Academic Division of Thoracic Surgery, Royal Brompton Hospital, London, United Kingdom.

Disclosures: Author has nothing to disclose with regard to commercial support.

Received for publication May 15, 2015; accepted for publication May 15, 2015; available ahead of print June 13, 2015.

Address for reprints: Eric Lim, MBChB, MD, MSc (Biostatistics), FRCS(C-Th), The Academic Division of Thoracic Surgery, Royal Brompton Hospital, Sydney St, London SW3 6NP, United Kingdom (E-mail: e.lim@rbht.nhs.uk).

J Thorac Cardiovasc Surg 2015;150:458-9

$0022-5223 / \$ 36.00$

Copyright (c) 2015 by The American Association for Thoracic Surgery

http://dx.doi.org/10.1016/j.jtcvs.2015.05.048
}

An alternative explanation is that surgeons with higher volume have better skill sets to undertake procedures such as sleeve lobectomies that would lower the pneumonectomy rates and possibly more segmentectomies to lower the wedge resection rate.

So who should offer what

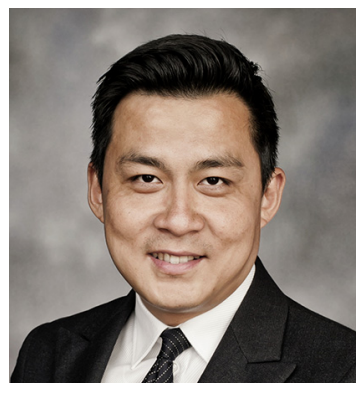
resection? Common arguments for not offering a more surgically technically challenging procedure sometimes centers on criticism of the procedure itself or explanations why it is not considered a "sound choice." These arguments hinge on the premise that there is evidence to support an appropriate resection extent for each presentation of surgically resectable lung cancer.

From a purely oncological perspective, the first and foremost consideration is complete cancer resection and to do it with loss to as little normal lung tissue as possible, but without increasing the risk of recurrence. The evidence for surgeons to back their selection of procedure that satisfies all 3 aims is a tall order.

For central tumors, intuitively, sleeve resection rather than pneumonectomy has the potential to achieve all 3 aims, but no randomized evidence exists, and none is likely to be generated because of small numbers and the lack of equipoise and willpower to initiate a randomized trial to answer the question definitively.

For peripheral tumors, many consider lobectomy as the standard of care (vs sublobar resection) based on the Lung Cancer Study Group 832, ${ }^{3}$ but the argument for wedge, segmentectomy, or lobectomy is evolving, especially as we are now detecting cancer at a much earlier stage, in particular adenocarcinoma presenting as ground-glass opacities on screening computed tomography. A randomized controlled trial evaluating lobectomy versus sublobar resection has recently completed accrual in Japan (JCOG0802/WJOG4607L), and another is currently recruiting in the United States (Cancer and Leukemia Group B 140503).

Until a good level of evidence exists, surgeons can argue either way. The pertinent question that follows from the work of Camposilvan and colleagues ${ }^{1}$ is to quantify any actual harm from pneumonectomy compared with sleeve resection or sublobar resection compared with lobectomy 
and the extent of practice variation that is considered unacceptable.

As a surgical community, it is incumbent on us to continue to evaluate surgical treatments generating the highest levels of evidence possible (randomized trials) and to have sufficient humility to cross-refer to colleagues when appropriate to ensure the best care for our patients.

\section{References}

1. Camposilvan I, Akhtar-Danesh N, Schneider L, Finley CJ. The effect of surgeon volume on procedure selection in non-small cell lung cancer surgeries. J Thorac Cardiovasc Surg. 2015;150:507-13.

2. Luchtenborg M, Riaz SP, Coupland VH, Lim E, Jakobsen E, Krasnik M, et al. High procedure volume is strongly associated with improved survival after lung cancer surgery. J Clin Oncol. 2013;31:3141-6.

3. Ginsberg RJ, Rubinstein LV. Randomized trial of lobectomy versus limited resection for T1 N0 non-small cell lung cancer. Lung Cancer Study Group. Ann Thorac Surg. 1995;60:615-23. 